\title{
Tyrosine Phosphorylation Regulates Rapid Endocytosis in Adrenal Chromaffin Cells
}

\author{
Paolo G. P. Nucifora and Aaron P. Fox \\ The University of Chicago, Department of Pharmacological and Physiological Sciences, Chicago, Illinois 60637
}

Secretion of neurotransmitter at the synapse and in secretory cells depends on the availability of vesicles for exocytosis. Rapid endocytosis is responsible for initiating local vesicle recycling and is essential during sustained neurotransmission. Although exocytosis is triggered by $\mathrm{Ca}^{2+}$ influx and modulated by serine/threonine kinases, relatively little is known about the regulation of rapid endocytosis. Our data suggest that rapid endocytosis is controlled by tyrosine phosphorylation. Treatment of bovine adrenal chromaffin cells with tyrphostin 23 , a protein tyrosine kinase inhibitor, dramatically slowed the time course of rapid endocytosis. In contrast, there was no effect on either the amount or rate of exocytosis. Application of orthovanadate, $\mathrm{Zn}^{2+}$, or poly(Glu, Tyr) $(4: 1)$, each of which is a tyrosine phosphatase inhibitor, reversed the effect of tyrphostin 23 on rapid endocytosis. Thus rapid endocytosis, like exocytosis, is subject to regulation by intracellular signaling pathways.

Key words: rapid endocytosis; tyrosine phosphorylation; adrenal chromaffin cells; exocytosis; tyrphostin 23; capacitance measurements
The plasma membrane of neurosecretory cells is in a state of dynamic equilibrium in which exocytosis is balanced by membrane reuptake via endocytosis (Betz et al., 1992; Ryan and Smith, 1995; Stevens and Tsujimoto, 1995; Betz and Angleson, 1998). Disruption of endocytosis is lethal in the Drosophila mutant shibire as a result of a defect in dynamin, a GTPase involved in the final steps of endocytosis (Chen et al., 1991). Recent work has suggested that the activity of proteins involved in rapid endocytosis, as in exocytosis, is determined by their phosphorylation state (Neher and Zucker, 1993; Robinson et al., 1994; Henkel and Betz, 1995; Vitale et al., 1995; Smith et al., 1998). Dynamin, for example, is phosphorylated by protein kinase $\mathrm{C}$ and may undergo stimulus-dependent dephosphorylation by calcineurin (Liu et al., 1994, 1996). The GTPase activity of dynamin, crucial for endocytosis, is inhibited by dephosphorylation [Robinson et al. (1993); but see Sever et al. (1999) for an alternate point of view]. The dephosphorylation of dynamin, synaptojanin, and amphiphysin enhances their formation into complexes (Bauerfeind et al., 1997; Slepnev et al., 1998). Calcineurin, a $\mathrm{Ca}^{2+}$ - and/or calmodulin-dependent phosphatase, promotes rapid endocytosis in some studies but acts as an inhibitor in others (Artalejo et al., 1996; Kuromi et al., 1997; Engisch and Nowycky, 1998; Marks and McMahon, 1998). Thus, protein kinase activity may represent a means by which endocytosis is coupled to excitation.

Ligand-dependent endocytosis, which is not coupled to secretion, is known to be regulated via tyrosine phosphorylation. Autophosphorylation of receptor tyrosine kinases initiates a cascade that leads to clathrin-mediated membrane internalization (Yarden and Schlessinger, 1987; Chang et al., 1993). Recently it

Received May 28, 1999; revised Aug. 23, 1999; accepted Sept. 1, 1999.

This work was supported by National Institutes of Health grants to A.P.F. and by Medical Scientist Training Program funding to P.G.P.N. We thank Drs. Kevin Currie and Chien-Yuan Pan for kindly preparing the chromaffin cells.

Correspondence should be addressed to Dr. Aaron P. Fox, The University of Chicago, Department of Pharmacological and Physiological Sciences, 947 East 58th Street, Chicago, IL 60637. E-mail: Aaron@Drugs.bsd.uchicago.edu.

Copyright (c) 1999 Society for Neuroscience 0270-6474/99/199739-08\$05.00/0 was shown that dynamin, required for both ligand-dependent endocytosis and rapid endocytosis, undergoes tyrosine phosphorylation after activation of the insulin receptor (Baron et al., 1998). Likewise, eps15, which may also be involved in endocytosis, is tyrosine phosphorylated by the epidermal growth factor (EGF) receptor kinase (Benmerah et al., 1995).

To determine whether rapid endocytosis is regulated in a manner similar to ligand-dependent endocytosis, we treated adrenal chromaffin cells with inhibitors of tyrosine kinases and phosphatases and observed the effects on rapid endocytosis. The tyrosine kinase inhibitor tyrphostin 23 (Yaish et al., 1988) caused a dramatic slowing in the kinetics of rapid endocytosis. The slowing could be reversed via the addition of orthovanadate, $\mathrm{Zn}^{2+}$, or poly(Glu, Tyr) (4:1), which are tyrosine phosphatase inhibitors (Swarup et al., 1982; Tonks et al., 1988; Walton and Dixon, 1993). The effect of tyrosine phosphorylation was specific to rapid endocytosis, because exocytosis was unaffected. In addition, tyrosine phosphorylation altered the kinetics but not the amount of rapid endocytosis. Our data suggest that rapid endocytosis is the specific target of one or more tyrosine kinase regulatory pathways.

\section{MATERIALS AND METHODS}

Cell culture. Bovine adrenal chromaffin cells were prepared from 18week-old animals as described previously (Artalejo et al., 1992). Adrenal glands were obtained from a local abattoir, digested with collagenase, and purified by density gradient centrifugation. Cells were plated with 10 $\mu \mathrm{M}$ arabinoside at a density of $0.15 \times 10^{6}$ cells $\mathrm{cm}^{-2}$ on collagen-coated glass coverslips and maintained for up to $96 \mathrm{hr}$ in an incubator at $37^{\circ} \mathrm{C}$ in an atmosphere of $92.5 \%$ air and $7.5 \% \mathrm{CO}_{2}$ with a relative humidity of $90 \%$. One-half of the incubation medium was changed every day. Experiments were performed 24-96 hr after preparing the cells. Cultures included both adrenaline- and noradrenaline-containing cells, although adrenaline constituted $65 \%$ of the total catecholamine content.

Electrophysiology. Stimulation consisted of a train of 10 depolarizations to either +10 or $+20 \mathrm{mV}$ (as noted) from a holding potential of -90 $\mathrm{mV}$. Depolarizations lasted $160 \mathrm{msec}$ and were separated by an interpulse interval of $380 \mathrm{msec}$. Capacitance was measured using the phasetracking technique (Joshi and Fernandez, 1988; Fidler and Fernandez, 1989), in which a $60 \mathrm{mV}$ peak-to-peak sine wave applied at $1.4 \mathrm{kHz}$ was 
added to the holding potential of $-90 \mathrm{mV}$, and the resulting current was analyzed at two orthogonal phase angles using a software-based phase sensitive detector. In all capacitance recordings, stimulations were applied 6 min after achieving whole-cell access. During stimulation of the cells, the sinusoidal signal was interrupted and then restarted after stimulation was complete. Depolarizations are indicated by gaps in the capacitance trace. All electrophysiological recordings were performed at room temperature using an Axopatch 1-B amplifier (Axon Instruments, Foster City, CA). Cell perfusion was performed with an Adams \& List (Westbury, NY) DAD-12 fast perfusion device.

Before achieving whole-cell access, cells were in a solution containing $140 \mathrm{~mm} \mathrm{NaCl}, 10 \mathrm{~mm}$ dextrose, $10 \mathrm{~mm}$ HEPES, $2.5 \mathrm{~mm} \mathrm{KCl}, 2 \mathrm{~mm}$ $\mathrm{MgCl}_{2}$, and $2 \mathrm{mM} \mathrm{CaCl}_{2}$, adjusted to $\mathrm{pH}$ 7.3. Immediately after achieving whole-cell access, the $\mathrm{CaCl}_{2}$ concentration in the bath was raised to 5 mM. Electrodes were pulled from microhematocrit capillary tubes (Drummond, Broomall, PA) and coated with Sylgard (Dow Corning, Midland, MI). The intracellular pipette solutions contained $110 \mathrm{~mm}$ Cs-aspartate, 20 mM HEPES, $100 \mu \mathrm{M}$ EGTA, 2 mM $\mathrm{MgCl}_{2}, 2$ mм ATP, $350 \mu \mathrm{M}$ GTP, and $14 \mathrm{~mm}$ creatine phosphate.

Where noted, $100 \mu \mathrm{M}$ tyrphostin 23 (Sigma, St. Louis, MO) was applied immediately after whole-cell access was achieved. Where noted, $250 \mu \mathrm{M} \mathrm{ZnCl}$ or $10 \mu \mathrm{M}$ poly(Glu, Tyr) (4:1) was included in the intracellular pipette solution. Of the 20 cells also exposed to the phosphatase inhibitor orthovanadate (Sigma), 15 cells were preincubated in 1 $\mathrm{mm}$ orthovanadate for up to $150 \mathrm{~min}$ at $37^{\circ} \mathrm{C}$ before being placed in the recording chamber. Recordings were performed in the continued presence of $1 \mathrm{~mm}$ orthovanadate. In these 15 experiments, $200 \mu \mathrm{M}$ orthovanadate was included in the intracellular pipette solution. In the remaining 5 experiments involving orthovanadate, $1 \mathrm{~mm}$ orthovanadate was not applied to the cells until immediately after whole-cell access was achieved, and no orthovanadate was present in the intracellular pipette solution.

In some experiments, cells were stimulated both in the presence and absence of tyrphostin 23, and whole-cell currents rather than capacitance were analyzed. In these experiments, the first stimulation occurred soon after achieving whole-cell access, before application of tyrphostin 23 . Then, $100 \mu \mathrm{M}$ tyrphostin 23 was added to the bath. After $6 \mathrm{~min}$ of treatment with tyrphostin 23 , cells were stimulated a second time. The extracellular $\left[\mathrm{Ca}^{2+}\right]$ was kept at $2 \mathrm{~mm}$ throughout these experiments.

Data analysis. The maximum rate of exocytosis was determined by finding the largest change in capacitance that occurred during a depolarization and dividing it by the $160 \mathrm{msec}$ duration of the depolarization. Total exocytosis was measured from the baseline before stimulation to the peak capacitance value that occurred within $10 \mathrm{sec}$ of stimulation. Rapid endocytosis was fit with either one or two exponentials during the fastest phase of capacitance decline. The amount of membrane retrieval was measured from the peak capacitance value during exocytosis to the minimum capacitance value within 2 min of stimulation. Many capacitance traces exhibited a plateau phase, during which exocytosis and rapid endocytosis were approximately balanced. To quantify the plateau time, the exponential decay function used to fit rapid endocytosis was extrapolated backward in time until its capacitance was equal to the peak capacitance value during exocytosis. The plateau time was defined as the difference between the time of peak capacitance and the time at which the exponential decay fitting function reached the same capacitance value. If this value was negative, the plateau time was defined as $0 \mathrm{sec}$. Significance tests were calculated using Student's $t$ test.

\section{RESULTS}

\section{Tyrosine kinase inhibition slows rapid endocytosis}

Capacitance measurements in bovine adrenal chromaffin cells were used to investigate the role of protein tyrosine kinases in the regulation of rapid endocytosis (Joshi and Fernandez, 1988; Fidler and Fernandez, 1989). Recordings were performed in a whole-cell patch-clamp configuration; stimulations consisted of a train of 10 depolarizations to $+10 \mathrm{mV}$ (except where noted) from a holding potential of $-90 \mathrm{mV}$. Figure $1 A$ shows a capacitance recording of a chromaffin cell undergoing stimulation. The trace has three components: a rising phase that reflects the net addition of membrane to the surface via exocytosis, a plateau phase in which exocytosis and endocytosis were approximately balanced,
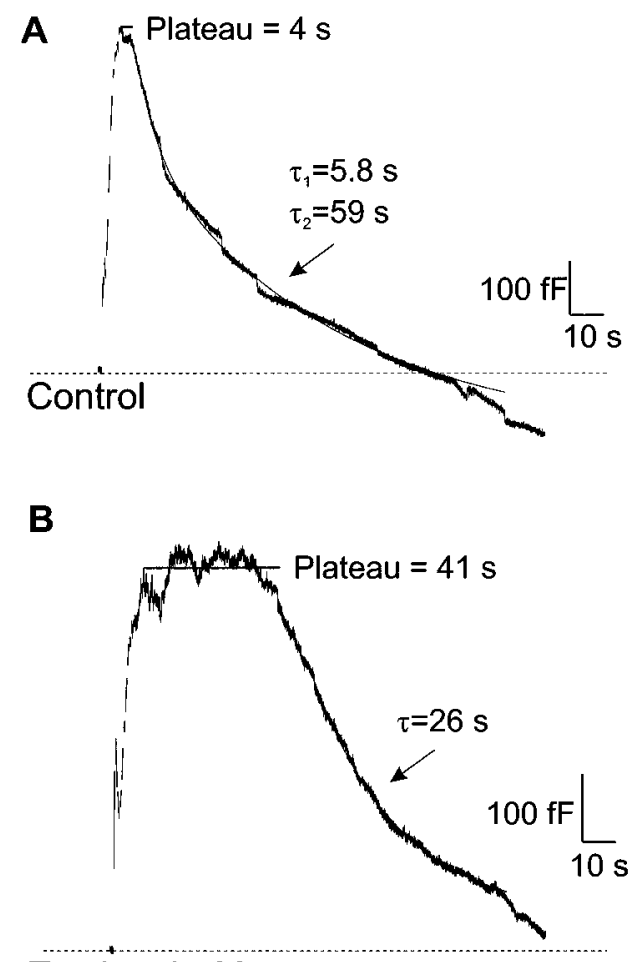

Tyrphostin 23

Figure 1. Tyrphostin 23 slowed the kinetics of rapid endocytosis. Exocytosis and rapid endocytosis were monitored using the capacitance technique on whole-cell patch-clamped bovine adrenal chromaffin cells. $A$, Capacitance recording of a control cell that underwent exocytosis during stimulation. Rapid endocytosis began after a short plateau phase. $B$, Capacitance recording of a cell treated with $100 \mu \mathrm{M}$ tyrphostin 23, a protein tyrosine kinase inhibitor. Exocytosis was similar to that in the control cell, but the plateau time was longer, and the fast time constant of rapid endocytosis was slower. Exponential fits to the data are indicated by the solid lines.

and a falling phase in which there was net retrieval of membrane from the surface via rapid endocytosis.

The maximum rate of exocytosis, $570 \mathrm{fF} / \mathrm{sec}$ in Figure $1 A$, was quantified as the maximum change in capacitance during the rising phase of the capacitance trace. Total exocytosis was measured from the baseline before stimulation to the peak capacitance value within $10 \mathrm{sec}$ of stimulation. The amount of retrieval was measured from the same peak to the minimum capacitance value in the 2 min after stimulation. This procedure may underestimate total exocytosis and retrieval because of overlap between exocytosis and rapid endocytosis. In this experiment, the amount of membrane retrieval approximately matched the amount of exocytosis. The time course of rapid endocytosis during the falling phase was fit as a double exponential with time constants of $5.8 \mathrm{sec}$ and $59 \mathrm{sec}$. To measure the plateau phase, we calculated the difference between the time at which the capacitance trace peaked and the time at which the double exponential used to fit rapid endocytosis reached the same capacitance value. By the use of this procedure, the calculated "plateau time" in Figure $1 A$ was $4 \mathrm{sec}$.

Rapid endocytosis was strikingly different in a cell stimulated after 6 min of treatment with the tyrosine kinase inhibitor tyrphostin $23(100 \mu \mathrm{M})$, as shown in Figure $1 B$. In this case the time course was fit with a single time constant of $26 \mathrm{sec}$. The plateau time was $41 \mathrm{sec}$. The longer plateau time is likely to indicate 
either a delay in the triggering of rapid endocytosis or a slowing of its initial components. The amount of endocytosis was approximately equal to that of exocytosis, indicating that tyrphostin 23 primarily affected the kinetics of rapid endocytosis. The maximum rate of exocytosis in this cell was $560 \mathrm{fF} / \mathrm{sec}$, similar to the value observed in Figure $1 A$. These results suggest that some component of rapid endocytosis is subject to continuous tyrosine phosphorylation, even under basal conditions.

To ensure that the response to tyrphostin 23 observed in Figure $1 B$ was specifically caused by an inhibition of tyrosine kinase activity, we attempted to reverse the response by inhibiting tyrosine phosphatases. Because our results suggest that ongoing tyrosine phosphorylation is necessary for rapid endocytosis, we expected tyrosine phosphatase inhibitors to counteract the effects of tyrosine kinase inhibitors. Figure 2 shows that the changes caused by tyrphostin 23 could be reversed by protein tyrosine phosphatase inhibition. The cell in Figure $2 A$ was pretreated for $25 \mathrm{~min}$ with $1 \mathrm{~mm}$ orthovanadate, a protein tyrosine phosphatase inhibitor, after which $100 \mu \mathrm{M}$ tyrphostin 23 was applied for $6 \mathrm{~min}$ in the continued presence of orthovanadate. After stimulation, both the time course of rapid endocytosis (time constants of 4.9 and $27 \mathrm{sec})$ and the plateau time $(0 \mathrm{sec})$ were comparable with those in Figure $1 A$. A different protein tyrosine phosphatase inhibitor, $250 \mu \mathrm{M} \mathrm{Zn}{ }^{2+}$, was dialyzed into the cell via the intracellular patch pipette (Fig. $2 B$ ) while $100 \mu \mathrm{M}$ tyrphostin 23 was simultaneously applied to the bath. Rapid endocytosis was similar to that in Figure $1 A$, with time constants of 4.9 and $120 \mathrm{sec}$. In this experiment the plateau time was $3 \mathrm{sec}$. In addition, $10 \mu \mathrm{M}$ poly(Glu, Tyr) (4:1), a peptide that inhibits tyrosine phosphatases, was dialyzed into the cell shown in Figure $2 C$ before application of tyrphostin 23. Rapid endocytosis had time constants of 2.9 and $54 \mathrm{sec}$. The plateau time was $2 \mathrm{sec}$. Thus, when protein tyrosine phosphatases were inhibited, tyrphostin 23 no longer altered either the kinetics of rapid endocytosis or the plateau phase.

The findings related to tyrosine phosphorylation are summarized in Figure 3. Rapid endocytosis was fit with either a single or double exponential; the data describing the fastest time constant are plotted in Figure $3 A$. The mean fast time constant of rapid endocytosis in control cells was $12 \pm 3 \mathrm{sec}(n=17)$. In the presence of tyrphostin 23 , the fast time constant was $36 \pm 5 \mathrm{sec}$ $(n=22)$, a value that is significantly longer than the control value $(p<0.002)$. Tyrosine phosphatase inhibitors reversed this increase. Rapid endocytosis had a average fast time constant of $13 \pm 3 \mathrm{sec}$ when tyrphostin 23 was applied with orthovanadate $(n=20), 9 \pm 4 \mathrm{sec}$ when tyrphostin 23 was applied in the presence of $\mathrm{Zn}^{2+}(n=6)$, and $16 \pm 5 \mathrm{sec}$ when tyrphostin 23 was applied with poly(Glu, Tyr) (4:1) $(n=6)$. (Only $71 \%$ of control cells required two time constants to fit endocytosis successfully, whereas the rest were well fit with a single time constant. In the cells that required a second slow time constant the average slow time constant was $105 \pm 22 \mathrm{sec}$ ).

The mean plateau time in control cells was $0.8 \pm 0.3 \mathrm{sec}$, as shown in Figure $3 B(n=17)$. In the presence of tyrphostin 23 the mean plateau time was $23 \pm 5 \mathrm{sec}(n=22)$, a value significantly longer than that in control cells $(p<0.0006)$. In contrast, cells cotreated with tyrphostin 23 and orthovanadate had a mean plateau time of $0.7 \pm 0.3 \mathrm{sec}(n=20)$. In cells cotreated with tyrphostin 23 and $\mathrm{Zn}^{2+}$ the mean plateau time was $2.2 \pm 0.6 \mathrm{sec}$ $(n=6)$, whereas cells cotreated with tyrphostin 23 and poly(Glu, Tyr) (4:1) had a mean plateau time of $8.7 \pm 8.1 \mathrm{sec}(n=6)$. The ability of tyrosine phosphatase inhibitors to reverse the effects of
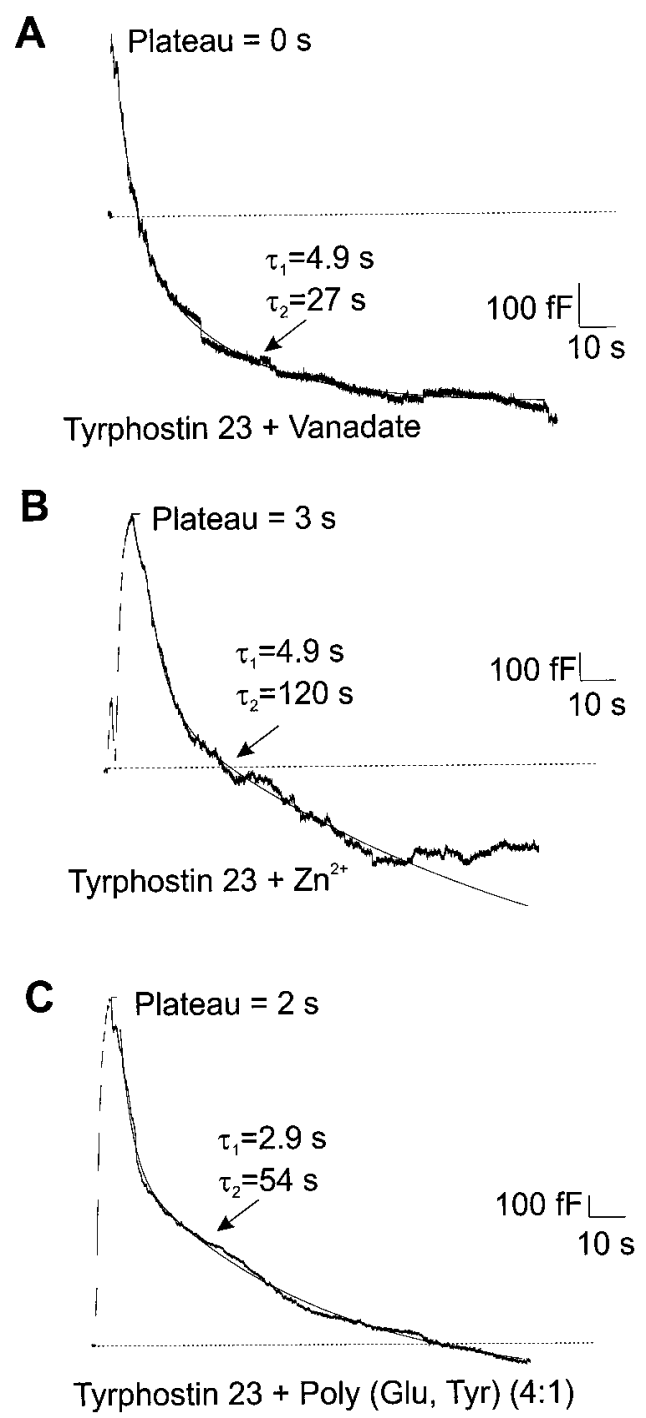

Figure 2. Slowing of rapid endocytosis by tyrphostin 23 was reversible. $A$, Capacitance recording of a cell treated with $1 \mathrm{~mm}$ orthovanadate and $100 \mu \mathrm{M}$ tyrphostin 23 (after a $25 \mathrm{~min}$ incubation with $1 \mathrm{~mm}$ orthovanadate). In the presence of orthovanadate, a protein tyrosine phosphatase inhibitor, tyrphostin 23 , had no effect on either the time course of rapid endocytosis or the plateau time. $B$, Capacitance recording of a cell treated

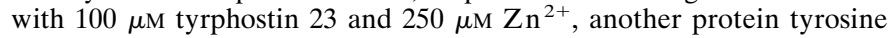
phosphatase inhibitor. The time course and kinetics of rapid endocytosis were similar to that in an untreated cell (see Fig. $1 A$ ). $C$, Capacitance recording of a cell treated with $100 \mu \mathrm{M}$ tyrphostin 23 and poly(Glu, Tyr) (4:1), a peptide inhibitor of tyrosine phosphatases. Like orthovanadate and $\mathrm{Zn}^{2+}$, this inhibitor reversed the effects of tyrphostin 23 on rapid endocytosis.

tyrphostin 23 suggests that its actions were mediated by tyrosine phosphorylation.

By themselves the tyrosine phosphatase inhibitors did not affect rapid endocytosis. Figure $4 A$ shows that cells treated with poly(Glu, Tyr) (4:1) had average fast time constants for rapid endocytosis that were not different from that of control cells. Figure $4 B$ shows that the amount of endocytosis in poly $(\mathrm{Glu}$, Tyr) (4:1)-treated cells was not different from that of control cells. Our data suggest that the effect of tyrosine phosphatase inhibitors was dependent on treating cells with tyrphostin 23 and reinforce the hypothesis that the actions were mediated by tyrosine phosphorylation. 


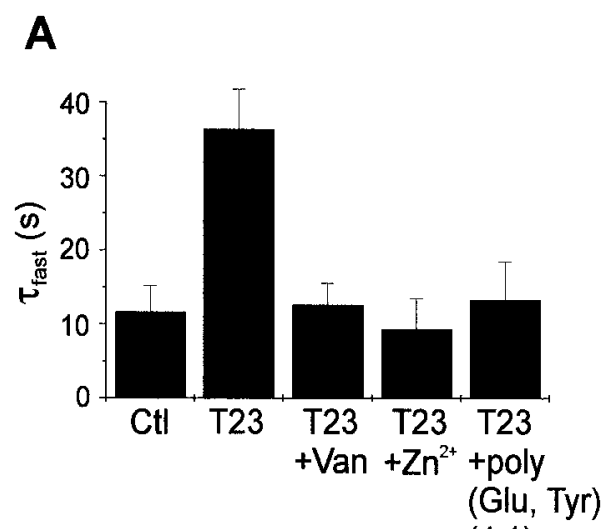

$(4: 1)$

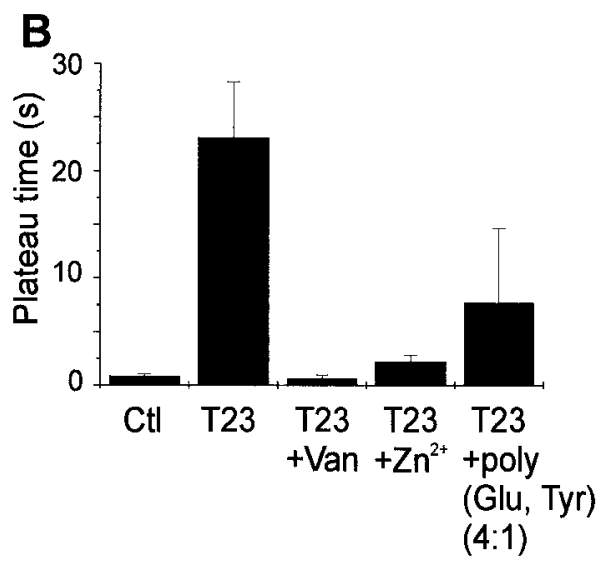

Figure 3. Tyrphostin 23 reversibly increased both the plateau time and the time constant of rapid endocytosis. $A$, The mean fast time constants of rapid endocytosis in cells treated with $100 \mu \mathrm{M}$ tyrphostin 23 (T23), with or without the protein tyrosine phosphatase inhibitors orthovanadate (Van), $\mathrm{Zn}^{2+}$, or poly(Glu, Tyr) (4:1), are shown. As compared with controls, tyrphostin 23 caused a significant increase in the time constant of rapid endocytosis $(p<0.002)$. However, the time constant of rapid endocytosis in cells treated with $100 \mu \mathrm{M}$ tyrphostin 23 and any of the three tyrosine phosphatase inhibitors was not significantly different from controls. $B$, The plateau time was also reversibly lengthened by tyrphostin 23 . Tyrphostin 23 caused a significant increase in the plateau time $(p<$ $0.0006)$, an effect that was reversed by orthovanadate, $\mathrm{Zn}^{2+}$, or poly(Glu, Tyr) (4:1). Ctl, Control.

\section{Tyrosine kinase inhibition does not affect the amount of membrane retrieval or exocytosis}

Although tyrphostin 23 had striking effects on the kinetics of rapid endocytosis, there was little effect on membrane retrieval. As shown in Figure $5 A$, the average amount of membrane retrieval during the falling phase of the capacitance trace was $480 \pm$ $60 \mathrm{fF}(n=17)$ in control cells. In the presence of tyrphostin 23 , the amount of rapid endocytosis was not significantly different $(500 \pm 80 \mathrm{fF} ; n=24)$. Tyrphostin 23 also had no effect on either the amount or kinetics of exocytosis, as shown in Figure 5, $B$ and $C$. Exocytosis in control cells caused a mean capacitance change of $470 \pm 80 \mathrm{fF}$ ( $n=17$; Fig. $5 B$ ), corresponding to the fusion of $\sim 360$ vesicles assuming that the average capacitance of an individual vesicle is $1.3 \mathrm{fF}$ (Moser and Neher, 1997). The maximum rate of exocytosis was $720 \pm 110 \mathrm{fF} / \mathrm{sec}(\sim 550$ vesicles/sec; Fig. $5 C$ ). In the presence of tyrphostin 23 , exocytosis caused a mean capacitance change of $570 \mathrm{fF}(\sim 440$ vesicles; $n=24)$, and its maximum rate was $850 \pm 260 \mathrm{fF} / \mathrm{sec}(\sim 650 \mathrm{vesicles} / \mathrm{sec})$, values
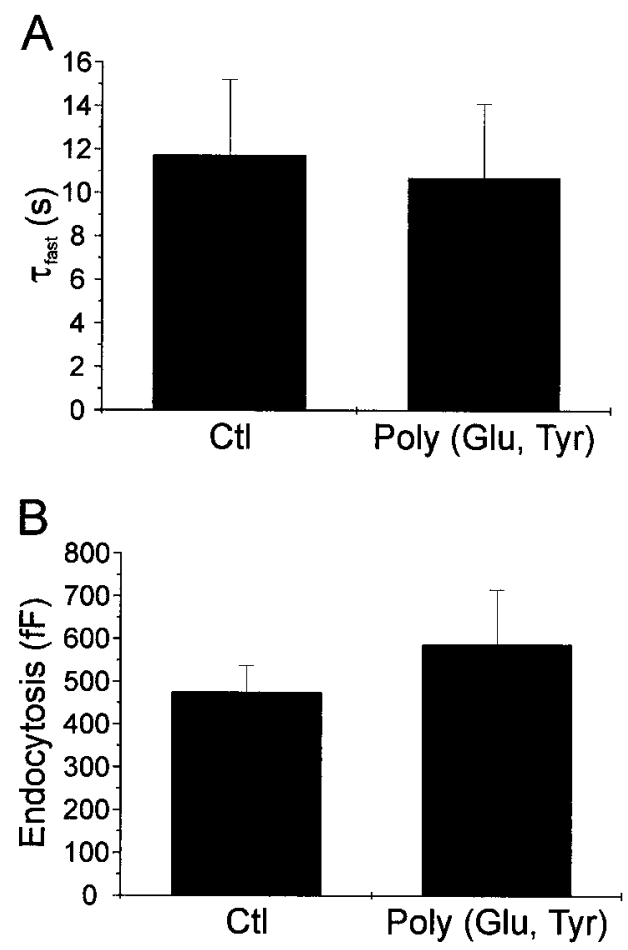

Figure 4. The protein tyrosine phosphatase inhibitor poly(Glu, Tyr) (4:1) had no effect on endocytosis when administered by itself. $A$, The mean fast time constants of rapid endocytosis in cells treated with or without the protein tyrosine phosphatase inhibitor poly(Glu, Tyr) (4:1) are shown. No change in the time constant of rapid endocytosis was observed [the control time constant was $11.7 \pm 3.5 \mathrm{sec}$, whereas the time constant in the presence of poly(Glu, Tyr) (4:1) was $10.7 \pm 3.4 \sec (n=$ $9)] . B$, The amount of membrane retrieved during rapid endocytosis was not altered by poly(Glu, Tyr) (4:1).

not significantly different from control values. Finally, the relationship between the total exocytosis and the amount of membrane retrieval was not affected by tyrphostin 23, as shown in Figure $5 D$. In both treated and untreated cells, the amount of membrane added to the cell via exocytosis was approximately equal to the amount of membrane retrieved.

\section{The effect of tyrosine phosphorylation on rapid endocytosis is not $\mathrm{Ca}^{2+}$ dependent}

The $\mathrm{Ca}^{2+}$ dependence of rapid endocytosis is still unclear (von Gersdorff and Matthews, 1994; Reuter and Porzig, 1995; Artalejo et al., 1996), although two recent reports suggest $\mathrm{Ca}^{2+}$ influx may trigger several components of rapid endocytosis (Smith and $\mathrm{Ne}$ her, 1997; Engisch and Nowycky, 1998). We found no significant difference in $\mathrm{Ca}^{2+}$ influx between cells treated with tyrphostin 23 and control cells, suggesting that the changes in rapid endocytosis induced by tyrphostin 23 were not mediated by alterations in $\mathrm{Ca}^{2+}$ influx. Figure 6 shows representative $\mathrm{Ca}^{2+}$ currents in a single cell before and after treatment with $100 \mu \mathrm{M}$ tyrphostin 23; treatment with tyrphostin 23 did not affect the $\mathrm{Ca}^{2+}$ current. Note that the early spike of inward current was carried by $\mathrm{Na}^{+}$.

Although $\mathrm{Ca}^{2+}$ influx in cells treated with tyrphostin 23 and either orthovanadate or $\mathrm{Zn}^{2+}$ was a little larger than that in cells treated with tyrphostin 23 alone, similar to that in smooth muscle cells (Wijetunge et al., 1998), this did not account for the tyrosine phosphatase inhibitor effects. We tested the effect of slightly 
A

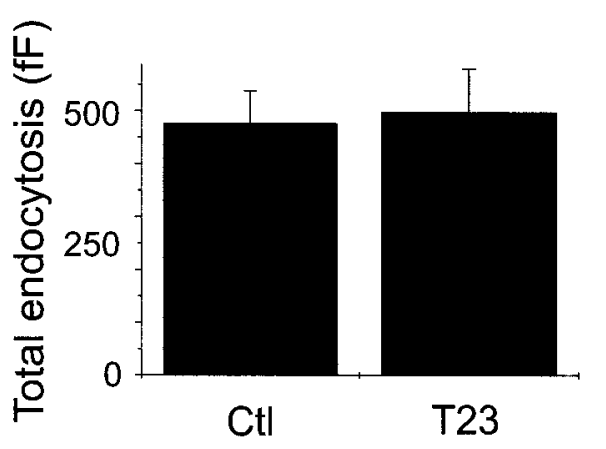

C

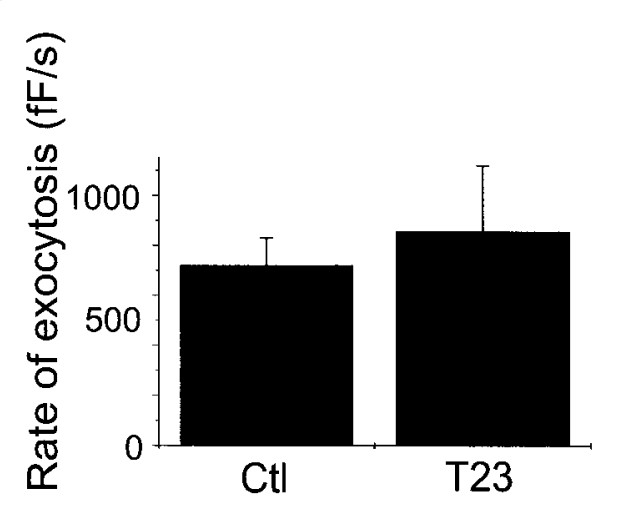

B

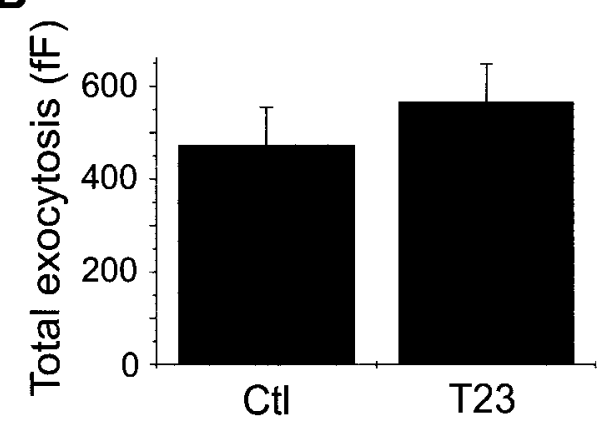

D

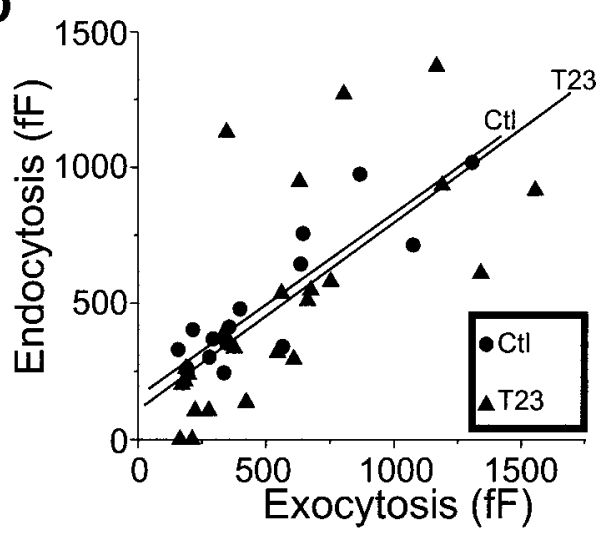

Figure 5. Tyrphostin 23 did not significantly affect exocytosis or the total amount of membrane retrieval. $A$, Membrane retrieval was similar in cells treated with tyrphostin 23 compared with control cells. Cotreatment with orthovanadate did not affect total membrane retrieval, although rapid endocytosis in cells treated with tyrphostin 23 and $\mathrm{Zn}^{2+}$ resulted in greater membrane retrieval than that in cells treated with tyrphostin 23 alone (data not shown). B, The mean total exocytosis, measured from baseline to the peak capacitance value within $10 \mathrm{sec}$ of stimulation, was not significantly different in tyrphostin 23 and control cells. Similarly, cotreatment with tyrphostin 23 and either $1 \mathrm{~mm}$ orthovanadate or $250 \mu \mathrm{M} \mathrm{Zn}{ }^{2+}$ did not have a significant effect on total exocytosis (data not shown). $C$, The maximum rate of exocytosis in tyrphostin 23 was not significantly different from that of control cells. Cotreatment with $\mathrm{Zn}^{2+}$ and tyrphostin 23 also had no significant effect, but the maximum rate of exocytosis in cells cotreated with orthovanadate and tyrphostin 23 was somewhat faster than that of cells treated with tyrphostin 23 alone (data not shown). Effects caused by one but not both protein tyrosine phosphatase inhibitors may reflect differences in the phosphatase specificity of each inhibitor or may indicate nonspe-

cific activities. $D$, Tyrphostin 23 did not affect membrane homeostasis. Total exocytosis is plotted as a function of the amount of membrane retrieval for control cells (circles) and cells treated with tyrphostin 23 (triangles). The least-squares regression line for control cells (top) and cells treated with tyrphostin 23 (bottom) is also plotted, showing that tyrphostin 23 did not affect the relationship between the amount of membrane added and membrane retrieved.

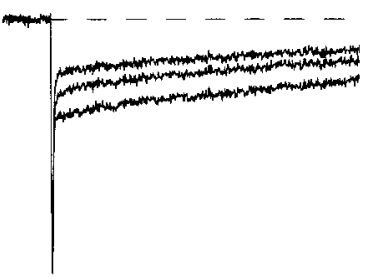

Before tyrphostin 23

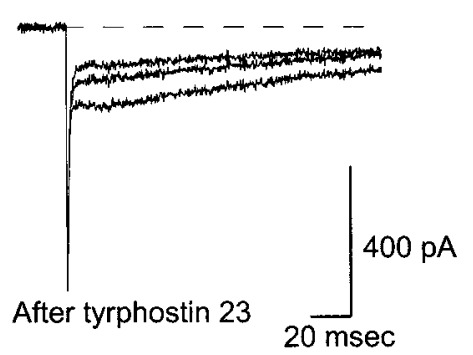

Figure 6. Tyrphostin 23 has no significant effect on $\mathrm{Ca}^{2+}$ currents. Whole-cell currents are shown from a cell stimulated before and after treatment with $100 \mu \mathrm{M}$ tyrphostin 23 . Only data from the first three depolarizations of a train are shown. Currents before treatment (left) are approximately equal to those after treatment with tyrphostin 23 (right). The extracellular $\left[\mathrm{Ca}^{2+}\right]$ was $2 \mathrm{~mm}$. Although $\mathrm{K}^{+}$currents were blocked by intracellular $\mathrm{Cs}^{+}$, no $\mathrm{Na}^{+}$channel inhibitors were used. The early spike in the current trace is carried by $\mathrm{Na}^{+}$. Neither the magnitude of the $\mathrm{Ca}^{2+}$ currents nor the rate of inactivation is affected by tyrosine kinase inhibition.

elevated $\mathrm{Ca}^{2+}$ influx by using a modified stimulation protocol that maximized $\mathrm{Ca}^{2+}$ currents. The test potential during the train of depolarizations was changed to $+20 \mathrm{mV}$, the peak of the $I-V$ curve for $\mathrm{Ca}$ channels (the test potential in all the figures shown in this manuscript is $+10 \mathrm{mV}$ ). The depolarization length, interpulse intervals, and external $\left[\mathrm{Ca}^{2+}\right]$ were otherwise unchanged. This small increase in $\mathrm{Ca}^{2+}$ influx did not alter rapid endocytosis in tyrphostin 23-treated cells (data not shown).

In addition to being potent broad spectrum tyrosine kinase
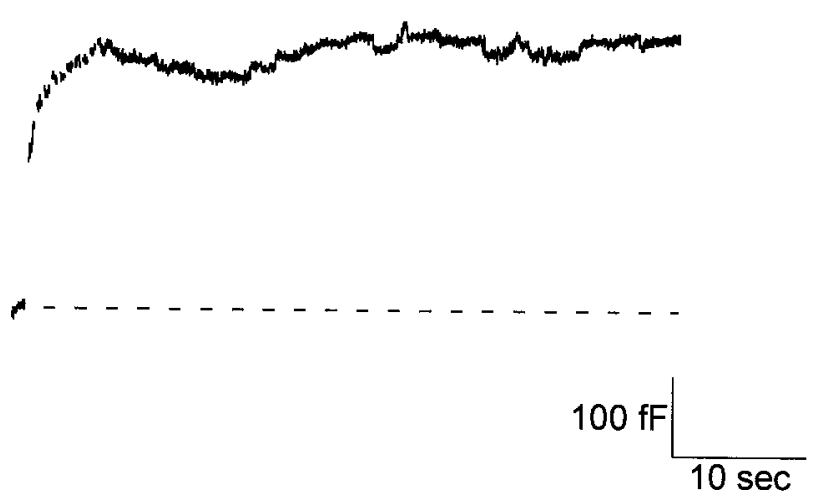

Figure 7. Rapid endocytosis was inhibited in cells dialyzed with GTP$\gamma$-S. Capacitance recording of a control cell that underwent exocytosis during stimulation but that showed no rapid endocytosis afterward. GTP$\gamma$-S $(350 \mu \mathrm{M})$ was dialyzed into the cell via the patch pipette. In five of eight cells dialyzed with GTP- $\gamma-\mathrm{S}$, there was little or no endocytosis present in the cells.

inhibitors, tyrphostins are effective inhibitors of certain GTPases (Wolbring et al., 1994). Although the tyrphostin 23-induced slowing of endocytosis is consistent with the inhibition of tyrosine kinases, we wanted to rule out possible effects on GTPases; experiments were performed using GTP- $\gamma$-S to inhibit GTPases. Figure 7 shows a capacitance trace obtained from a cell dialyzed with $350 \mu \mathrm{M}$ GTP- $\gamma$-S. Most cells treated in this way showed little or no endocytosis, consistent with a study by Artalejo et al. (1995), which showed that GTP- $\gamma$-S inhibited endocytosis. Thus, GTP- $\gamma$-S does not mimic tyrphostin 23 , which slows endocytosis 
but does not change total membrane retrieval. Our results suggest that tyrphostin 23 operates by inhibiting tyrosine kinases, not GTPases.

\section{DISCUSSION}

Since the discovery that nerve growth factor acts by stimulating the tyrosine kinase activity of a surface membrane receptor (Kaplan et al., 1991; Klein et al., 1991), interest has surged in the role of tyrosine phosphorylation in the nervous system. Receptor tyrosine kinases are now known to have a variety of roles in neuronal growth and development. For example, Eph-related receptor tyrosine kinases play a prominent part in establishing the topography of retinotectal projections (Drescher, 1997). There is also an increasing recognition of the regulatory actions of tyrosine phosphatases, such as DPTP69D. When mutated in Drosophila, this tyrosine phosphatase causes abnormal motor neuron development (Desai et al., 1996; Krueger et al., 1996). Our data indicate another important physiological role for tyrosine phosphorylation. In adrenal chromaffin cells tyrosine phosphorylation helps to regulate rapid endocytosis. Furthermore, this new regulatory function specifically affects the kinetics of rapid endocytosis, while leaving exocytosis unaffected.

Receptor tyrosine kinases have a well-established role in the initiation of ligand-dependent endocytosis. Mutations that reduce the tyrosine kinase activity of the EGF receptor may also inhibit ligand-dependent endocytosis (Lamaze and Schmid, 1995). After undergoing autophosphorylation, the EGF receptor has an increased affinity for the coated pit adaptor protein in complex AP2 (Nesterov et al., 1995). The EGF receptor also phosphorylates eps15, an AP2-binding protein that promotes clathrin assembly (Benmerah et al., 1995, 1998). The GTPase dynamin, a key component of endocytosis, undergoes tyrosine phosphorylation after activation of the insulin receptor, although the functional consequences of phosphorylation are unknown (Chen et al., 1991; Baron et al., 1998).

Rapid endocytosis does not require binding of an extracellular ligand, because our fast perfusion system ensured that all potential ligands were rapidly washed away. Nevertheless, rapid endocytosis shares many similarities with ligand-dependent endocytosis. Dynamin, for example, is necessary in both types of endocytosis (Koenig and Ikeda, 1989; Morris and Schmid, 1995). Inhibition of dynamin with GTP- $\gamma-\mathrm{S}$ is thought to abolish rapid endocytosis in chromaffin cells (Artalejo et al., 1995), an observation consistent with the data in this manuscript. Our work shows that rapid endocytosis, like ligand-dependent endocytosis, is regulated by tyrosine phosphorylation. Treatment of adrenal chromaffin cells with the tyrosine kinase inhibitor tyrphostin 23 slowed the time course of rapid endocytosis. This effect was reversed by the addition of three different tyrosine phosphatase inhibitors, indicating that the slowing of rapid endocytosis was mediated by changes in tyrosine phosphorylation rather than by tyrphostin-mediated changes in GTP metabolism (Wolbring et al., 1994). In contrast to GTP- $\gamma$-S, which blocked endocytosis in most cells, tyrphostin 23 slowed rapid endocytosis with no effect on the total amount of membrane retrieval. Slowing of rapid endocytosis was observed soon after application of tyrphostin 23, but there was no effect on the total amount of membrane retrieval. This indicates that tyrosine kinases specifically govern the kinetics, not the amount, of membrane retrieval. The kinetic effects of tyrosine kinases may be crucial under conditions of strong stimulation because rapid endocytosis may be rate-limiting in such circumstances (Klingauf et al., 1998). In contrast, on longer time scales rapid endocytosis may act to maintain surface area homeostasis (Ceccarelli et al., 1972; Heuser and Reese, 1973); our results suggest that tyrosine kinases are less likely to be directly involved in the regulation of this process.

Dynamic tyrosine phosphorylation plays an important part in modulating synaptic efficiency. The inhibition of $\mathrm{N}$-type $\mathrm{Ca}^{2+}$ channels by $\mathrm{GABA}_{\mathrm{B}}$ receptor activation can be partially blocked by treatment with tyrosine kinase inhibitors (Diverse-Pierluissi et al., 1997). Tyrosine kinases also regulate voltage-dependent facilitation of T-type $\mathrm{Ca}^{2+}$ channels (Arnoult et al., 1997) and $\mathrm{Ca}^{2+}$ currents in smooth muscle cells (Wijetunge et al., 1998). Although there is evidence of a role for $\mathrm{Ca}^{2+}$ in the control of rapid endocytosis (Neher and Zucker, 1993; Smith and Neher, 1997; Engisch and Nowycky, 1998), we did not observe significant changes in $\mathrm{Ca}^{2+}$ influx in chromaffin cells after treatment with tyrphostin 23. Consequently, the slowing of rapid endocytosis by tyrosine kinase inhibition was probably mediated by a novel synaptic regulatory mechanism. This conclusion is supported by the finding that rapid endocytosis was slowed even in experiments specifically designed to increase $\mathrm{Ca}^{2+}$ influx (data not shown).

Neither the rate nor the amount of exocytosis was significantly affected by tyrphostin 23 . Because exocytosis is known to be a $\mathrm{Ca}^{2+}$-dependent process, this is consistent with our observations that $\mathrm{Ca}^{2+}$ influx was not affected by tyrosine kinase inhibition. These findings are especially intriguing because a study by Cox et al. (1996) showed that tyrphostin 23 and other tyrosine kinase inhibitors significantly reduced catecholamine secretion by adrenal chromaffin cells. It is important to note that the stimulations in their work were approximately two orders of magnitude longer than those described in this paper. Long-term failure of catecholamine secretion after treatment with tyrphostin 23 , which quickly interferes with rapid endocytosis, suggests that competent endocytosis may be necessary for cells to maintain exocytosis for extended periods, and interference with endocytosis may impair the mobilization of filled granules.

At least two kinetic parameters were altered by tyrphostin 23: the time constant of rapid endocytosis and the plateau time. The plateau phase most likely reflects a slowing or delay in the onset of rapid endocytosis. Alternately, the longer plateau time might reflect an upregulation of exocytosis that was precisely balanced by rapid endocytosis. The latter hypothesis seems unlikely because longer plateau times were associated with slower time constants of rapid endocytosis, and there was no evidence of a change in exocytosis during the rising phase of the capacitance trace. Furthermore, a recent study has shown that neurotransmitter release ends $<1 \mathrm{sec}$ after stimulation (Albillos et al., 1997). These findings argue that the primary effect of tyrphostin 23 was on the kinetics of rapid endocytosis, although the possibility remains that multiple regulatory components of rapid endocytosis are tyrosine phosphorylated.

What is the target of tyrosine phosphorylation in rapid endocytosis? It is tempting to speculate that dynamin is tyrosine phosphorylated in rapid endocytosis as well as in liganddependent endocytosis. Alternately, our observations may reflect a requirement for the phosphorylation of other proteins, such as eps15. Finally, although the kinase(s) required for rapid endocytosis has not yet been identified, many proteins involved in rapid endocytosis interact with src, including dynamin, synapsin Ia, and synapsin Ib (Onofri et al., 1997; Foster-Barber and Bishop, 1998). Src is thought to promote ligand-dependent endocytosis (Ware et al., 1997), and the src family kinase fyn is activated during 
stimulation in adrenal chromaffin cells (Allen et al., 1996). Thus, activation of src family kinases might represent a common pathway for ligand-dependent endocytosis and rapid endocytosis.

\section{REFERENCES}

Albillos A, Dernick G, Horstmann H, Almers W, Alvarez de Toledo G, Lindau M (1997) The exocytotic event in chromaffin cells revealed by patch amperometry. Nature 389:509-512.

Allen CM, Ely CM, Juaneza MA, Parsons SJ (1996) Activation of Fyn tyrosine kinase upon secretagogue stimulation of bovine chromaffin cells. J Neurosci Res 44:421-429.

Arnoult C, Lemos JR, Florman HM (1997) Voltage-dependent modulation of T-type calcium channels by protein tyrosine phosphorylation. EMBO J 16:1593-1599.

Artalejo CR, Perlman RL, Fox AP (1992) Omega-conotoxin GVIA blocks a $\mathrm{Ca} 2+$ current in bovine chromaffin cells that is not of the "classic" N type. Neuron 8:85-95.

Artalejo CR, Henley JR, McNiven MA, Palfrey HC (1995) Rapid endocytosis coupled to exocytosis in adrenal chromaffin cells involves $\mathrm{Ca}^{2+}$, GTP, and dynamin but not clathrin. Proc Natl Acad Sci USA 92:8328-8332.

Artalejo CR, Elhamdani A, Palfrey HC (1996) Calmodulin is the divalent cation receptor for rapid endocytosis, but not exocytosis, in adrenal chromaffin cells. Neuron 16:195-205.

Baron V, Alengrin F, Van Obberghen E (1998) Dynamin associates with Src-homology collagen (Shc) and becomes tyrosine phosphorylated in response to insulin. Endocrinology 139:3034-3037.

Bauerfeind R, Takei K, De Camilli P (1997) Amphiphysin I is associated with coated endocytic intermediates and undergoes stimulationdependent dephosphorylation in nerve terminals. J Biol Chem 272:30984-30992.

Benmerah A, Gagnon J, Begue B, Megarbane B, Dautry-Varsat A, Cerf-Bensussan N (1995) The tyrosine kinase substrate eps15 is constitutively associated with the plasma membrane adaptor AP-2. J Cell Biol 131:1831-1838.

Benmerah A, Lamaze C, Begue B, Schmid SL, Dautry-Varsat A, CerfBensussan N (1998) AP-2/Eps15 interaction is required for receptormediated endocytosis. J Cell Biol 140:1055-1062.

Betz WJ, Angleson JK (1998) The synaptic vesicle cycle. Annu Rev Physiol 60:347-363.

Betz WJ, Mao F, Bewick GS (1992) Activity-dependent fluorescent staining and destaining of living vertebrate motor nerve terminals. J Neurosci 12:363-375.

Ceccarelli B, Hurlbut WP, Mauro A (1972) Depletion of vesicles from frog neuromuscular junctions by prolonged tetanic stimulation. J Cell Biol 54:30-38.

Chang CP, Lazar CS, Walsh BJ, Komuro M, Collawn JF, Kuhn LA, Tainer JA, Trowbridge IS, Farquhar MG, Rosenfeld MG (1993) Ligand-induced internalization of the epidermal growth factor receptor is mediated by multiple endocytic codes analogous to the tyrosine motif found in constitutively internalized receptors. J Biol Chem 268:19312-19320.

Chen MS, Obar RA, Schroeder CC, Austin TW, Poodry CA, Wadsworth SC, Vallee RB (1991) Multiple forms of dynamin are encoded by shibire, a Drosophila gene involved in endocytosis. Nature 351:583-586.

Cox ME, Ely CM, Catling AD, Weber MJ, Parsons SJ (1996) Tyrosine kinases are required for catecholamine secretion and mitogen-activated protein kinase activation in bovine adrenal chromaffin cells. J Neurochem 66:1103-1112.

Desai CJ, Gindhart Jr JG, Goldstein LS, Zinn K (1996) Receptor tyrosine phosphatases are required for motor axon guidance in the Drosophila embryo. Cell 84:599-609.

Diverse-Pierluissi M, Remmers AE, Neubig RR, Dunlap K (1997) Novel form of crosstalk between $G$ protein and tyrosine kinase pathways. Proc Natl Acad Sci USA 94:5417-5421.

Drescher U (1997) The Eph family in the patterning of neural development. Curr Biol 7:R799-R807.

Engisch KL, Nowycky MC (1998) Compensatory and excess retrieval: two types of endocytosis following single step depolarizations in bovine adrenal chromaffin cells. J Physiol (Lond) 506:591-608.

Fidler N, Fernandez JM (1989) Phase tracking: an improved phase de- tection technique for cell membrane capacitance measurements. Biophys J 56:1153-1162.

Foster-Barber A, Bishop JM (1998) Src interacts with dynamin and synapsin in neuronal cells. Proc Natl Acad Sci USA 95:4673-4677.

Henkel AW, Betz WJ (1995) Staurosporine blocks evoked release of FM1-43 but not acetylcholine from frog motor nerve terminals. J Neurosci 15:8246-8258.

Heuser JE, Reese TS (1973) Evidence for recycling of synaptic vesicle membrane during transmitter release at the frog neuromuscular junction. J Cell Biol 57:315-344.

Joshi C, Fernandez JM (1988) Capacitance measurements. An analysis of the phase detector technique used to study exocytosis and endocytosis. Biophys J 53:885-892.

Kaplan DR, Hempstead BL, Martin-Zanca D, Chao MV, Parada LF (1991) The trk proto-oncogene product: a signal transducing receptor for nerve growth factor. Science 252:554-558.

Klein R, Jing SQ, Nanduri V, O'Rourke E, Barbacid M (1991) The trk proto-oncogene encodes a receptor for nerve growth factor. Cell 65:189-197.

Klingauf J, Kavalali ET, Tsien RW (1998) Kinetics and regulation of fast endocytosis at hippocampal synapses. Nature 394:581-585.

Koenig JH, Ikeda K (1989) Disappearance and reformation of synaptic vesicle membrane upon transmitter release observed under reversible blockage of membrane retrieval. J Neurosci 9:3844-3860.

Krueger NX, Van Vactor D, Wan HI, Gelbart WM, Goodman CS, Saito H (1996) The transmembrane tyrosine phosphatase DLAR controls motor axon guidance in Drosophila. Cell 84:611-622.

Kuromi H, Yoshihara M, Kidokoro Y (1997) An inhibitory role of calcineurin in endocytosis of synaptic vesicles at nerve terminals of Drosophila larvae. Neurosci Res 27:101-113.

Lamaze C, Schmid SL (1995) Recruitment of epidermal growth factor receptors into coated pits requires their activated tyrosine kinase. J Cell Biol 129:47-54.

Liu JP, Sim AT, Robinson PJ (1994) Calcineurin inhibition of dynamin I GTPase activity coupled to nerve terminal depolarization. Science 265:970-973.

Liu JP, Zhang QX, Baldwin G, Robinson PJ (1996) Calcium binds dynamin I and inhibits its GTPase activity. J Neurochem 66:2074-2081.

Marks B, McMahon HT (1998) Calcium triggers calcineurin-dependent synaptic vesicle recycling in mammalian nerve terminals. Curr Biol 8:740-749.

Morris SA, Schmid SL (1995) Synaptic vesicle recycling. The Ferrari of endocytosis? Curr Biol 5:113-115.

Moser T, Neher E (1997) Estimation of mean exocytic vesicle capacitance in mouse adrenal chromaffin cells. Proc Natl Acad Sci USA 94:6735-6740.

Neher E, Zucker RS (1993) Multiple calcium-dependent processes related to secretion in bovine chromaffin cells. Neuron 10:21-30.

Nesterov A, Kurten RC, Gill GN (1995) Association of epidermal growth factor receptors with coated pit adaptins via a tyrosine phosphorylation-regulated mechanism. J Biol Chem 270:6320-6327.

Onofri F, Giovedi S, Vaccaro P, Czernik AJ, Valtorta F, De Camilli P, Greengard P, Benfenati F (1997) Synapsin I interacts with c-Src and stimulates its tyrosine kinase activity. Proc Natl Acad Sci USA 94:12168-12173.

Reuter H, Porzig H (1995) Localization and functional significance of the $\mathrm{Na}+/ \mathrm{Ca} 2+$ exchanger in presynaptic boutons of hippocampal cells in culture. Neuron 15:1077-1084.

Robinson PJ, Sontag JM, Liu JP, Fykse EM, Slaughter C, McMahon H, Sudhof TC (1993) Dynamin GTPase regulated by protein kinase C phosphorylation in nerve terminals. Nature 365:163-166.

Robinson PJ, Liu JP, Powell KA, Fykse EM, Sudhof TC (1994) Phosphorylation of dynamin I and synaptic-vesicle recycling. Trends Neurosci 17:348-353.

Ryan TA, Smith SJ (1995) Vesicle pool mobilization during action potential firing at hippocampal synapses. Neuron 14:983-989.

Sever S, Muhlberg AB, Schmid SL (1999) Impairment of dynamin's GAP domain stimulates receptor-mediated endocytosis. Nature 398:481-486.

Slepnev VI, Ochoa GC, Butler MH, Grabs D, Camilli PD (1998) Role of phosphorylation in regulation of the assembly of endocytic coat complexes. Science 281:821-824.

Smith C, Neher E (1997) Multiple forms of endocytosis in bovine adrenal chromaffin cells. J Cell Biol 139:885-894.

Smith C, Moser T, Xu T, Neher E (1998) Cytosolic Ca2+ acts by two 
separate pathways to modulate the supply of release-competent vesicles in chromaffin cells. Neuron 20:1243-1253.

Stevens CF, Tsujimoto T (1995) Estimates for the pool size of releasable quanta at a single central synapse and for the time required to refill the pool. Proc Natl Acad Sci USA 92:846-849.

Swarup G, Cohen S, Garbers DL (1982) Inhibition of membrane phosphotyrosyl-protein phosphatase activity by vanadate. Biochem Biophys Res Commun 107:1104-1109.

Tonks NK, Diltz CD, Fischer EH (1988) Characterization of the major protein-tyrosine-phosphatases of human placenta. J Biol Chem 263:6731-6737.

Vitale ML, Seward EP, Trifaro JM (1995) Chromaffin cell cortical actin network dynamics control the size of the release-ready vesicle pool and the initial rate of exocytosis. Neuron 14:353-363.

von Gersdorff H, Matthews G (1994) Inhibition of endocytosis by elevated internal calcium in a synaptic terminal. Nature 370:652-655.
Walton KM, Dixon JE (1993) Protein tyrosine phosphatases. Annu Rev Biochem 62:101-120.

Ware MF, Tice DA, Parsons SJ, Lauffenburger DA (1997) Overexpression of cellular Src in fibroblasts enhances endocytic internalization of epidermal growth factor receptor. J Biol Chem 272:30185-30190.

Wijetunge S, Lymn JS, Hughes AD (1998) Effect of inhibition of tyrosine phosphatases on voltage-operated calcium channel currents in rabbit isolated ear artery cells. Br J Pharmacol 124:307-316.

Wolbring G, Hollenburg MD, Schnetkamp PPM (1994) Inhibition of GTP-utilizing enzymes by tyrphostins. J Biol Chem 269:22470-22472.

Yaish P, Gazit A, Gilon C, Levitzki A (1988) Blocking of EGFdependent cell proliferation by EGF receptor kinase inhibitors. Science 242:933-935.

Yarden Y, Schlessinger J (1987) Self-phosphorylation of epidermal growth factor receptor: evidence for a model of intermolecular allosteric activation. Biochemistry 26:1434-1442. 